\title{
QUALIDADE MICROBIOLÓGICA DO SUSHI COMERCIALIZADO NA CIDADE DE SOBRAL-CE
}

\author{
Rosângela Maria Almeida MOUTA ${ }^{1}$ \\ Monica Brandão MELO ${ }^{2}$ \\ Ana Bruna de ARAÚJO3 \\ Francisca Lidiane Linhares de AGUIAR ${ }^{4}$ \\ Raquel Oliveira dos Santos FONTENELLE ${ }^{5}$
}

\begin{abstract}
${ }^{1}$ Centro de Ciências Agrárias e Biológicas, Discente do curso de Ciências Biológicas pela Universidade Estadual Vale do Acaraú. E-mail: rosangela_almeida_mouta@ hotmail.com

${ }^{2}$ Graduada em Ciências Biológica pela Universidade Estadual Vale do Acaraú. E-mail: monykabrandao@ hotmail.com

${ }^{3}$ Mestranda em Biotecnologia pela Universidade Federal do Ceará. E-mail: ana_bruna17@ hotmail.com

${ }^{4}$ Centro de Ciência e Tecnologia, Mestranda em Recursos Naturais pela Universidade Estadual do Ceará. Email:lidianelinhares@yahoo.com.br

${ }^{5}$ Centro de Ciências Agrárias e Biológicas, Professora efetiva do Curso de Biologia da Universidade Estadual Vale do Acaraú. E-mail: raquelbios@yahoo.com.br
\end{abstract}

Recebido em: 30/05/2014 - Aprovado em: 15/09/2014 - Disponibilizado em: 15/12/2014

RESUMO: O sushi é um alimento feito à base de arroz temperado com molho de vinagre, açúcar e sal, combinado com algum tipo cru de peixe ou fruto do mar, mas como muitos alimentos que utilizam estes ingredientes o sushi não está livre de riscos á saúde, que se torna uma preocupação em relação à contaminação por bactérias. Este trabalho tem como objetivo avaliar a qualidade microbiológica do sushi comercializado em pontos não especializados e especializado na cidade de Sobra-CE, para verificar a presença de coliformes totais e termotolerantes através da técnica dos tubos múltiplos e notificar se estão de acordo com a legislação vigente. Foram detectada a presença de coliformes totais e termotolerantes em todas as amostras de sushis o que pode a vim ser um risco para a população.

Palavras-chave: Sushi. Consumo. Qualidade

\section{INTRODUÇÃO}

Durante algum tempo, o brasileiro estabelece novas formas de consumo alimentar, passando a incluir na dieta produtos que contenham proteínas e sais minerais. Como exemplo dessa mudança temos o sushi, tradicionalmente feito com arroz temperado com molho de vinagre, açúcar e sal, ao qual é combinado com algum tipo de peixe ou frutos do mar, ou ainda vegetais, frutas ou até mesmo ovo. A tradição japonesa é de servi-lo acompanhado de wasabi e shoyu (molho de soja). (BARBER; TAKEMURA, 2002)

A globalização dos hábitos alimentares gerou a propagação do consumo do peixe cru, originário da culinária japonesa. Com isso, vários estabelecimentos especializados nesta culinária surgiram em cidades ocidentais. Além dos restaurantes especializados tais iguarias podem também ser encontradas em restaurantes não especializados, como churrascarias e restaurantes a peso (EDWARD, 2012). 
A qualidade do peixe fresco pode ser influenciada por hábitos não higiênicos dos manipuladores, podendo comprometer a qualidade higiênico-sanitária do alimento, o consumo do pescado in natura representa um grande risco à saúde coletiva, por não haver as barreiras térmicas (cocção) para esterilização do alimento e assim garantir sua inocuidade (CORREIA; RONCADA 2002).

A necessidade do controle da qualidade dos produtos alimentícios está bem registrada e, uma vez que as doenças de origem alimentar, convencionalmente chamadas de Doenças Transmitidas por Alimentos (DTA) têm aumentado a cada ano, há também uma necessidade urgente de melhorar os meios tradicionais e atuais para assegurar a qualidade dos alimentos (MALAVOTA, 2008). Embora a diarreia seja o sintoma mais comum de DTA, outras séries consequências, incluindo problemas nos rins e fígado, desordens neurológicas e até morte, podem ocorrer. (SCHLUNDT, 2002)

Este trabalho tem como objetivo avaliar a qualidade microbiológica do sushi comercializado em estabelecimentos não especializados e especializado na cidade de Sobral -CE.

\section{MATERIAIS E MÉTODOS}

\section{Amostragem}

Foram coletadas amostras de quatro pontos, sendo três de locais não especializados e um de ambiente especializado. As amostras foram transportadas em embalagens disponibilizadas pelos próprios estabelecimentos e levadas imediatamente para o laboratório de microbiologia da Universidade Estadual Vale do Acaraú, onde foram realizadas as análises.

\section{Diluições}

Para inicio da análise microbiológica, foram pesados $25 \mathrm{~g}$ de cada amostra e diluídas através da agitação em $225 \mathrm{ml}$ de cloreto de sódio a $0,85 \%$ por três minutos (diluição $10^{-}$ ${ }^{1}$ ). A partir dessa diluição foram preparadas as demais, retirando-se $1 \mathrm{~mL}$ da diluição anterior e diluindo em $9 \mathrm{~mL}$ de salina, até a diluição $10^{-3}$. Para a contagem de coliformes foi utilizada a técnica do Número Mais Provável (NMP).

\section{Teste presuntivo}

Para a prova presuntiva utilizou-se 10 $\mathrm{mL}$ de caldo lactosado com tubos de Durham invertidos, distribuídos em três séries de cinco repetições. Na primeira série, os tubos foram inoculados com $1 \mathrm{~mL}$ da diluição $10^{-1}$, a segunda foi inoculada com $1 \mathrm{~mL}$ da diluição $10^{-2}$ e a terceira série foi inoculada com $1 \mathrm{~mL}$ da diluição $10^{-3}$. Em seguida, os tubos foram incubados em estufa a $36^{\circ} \mathrm{C}$ por um período de 48 h. Foram considerados positivos os tubos que apresentaram produção de gás no tubo de Durham. 


\section{Teste confirmativo}

Para a quantificação de coliformes totais foram retiradas alíquotas, com auxílio de uma alça de cromo níquel, dos tubos positivos de lactosado (com presença de gás nos tubos de Durham) e inoculadas em tubos contendo Caldo Bile Verde Brilhante (BVB) com tubos de Durham invertidos. Em seguida os tubos foram incubados em estufa a $36{ }^{\circ} \mathrm{C}$ por $48 \mathrm{~h}$. Os tubos que apresentaram formação de gás dentro dos tubos de Durham foram considerados positivos.

Para a enumeração de coliformes termotolerantes, as alíquotas dos tubos de lactosado positivos foram transferidas para tubos contendo caldo Escherichia coli (EC), com tubos de Durham invertidos. Em seguida foram incubados em banho Maria a $44{ }^{0} \mathrm{C}$ por 48 h. Os tubos que apresentaram formação de gás foram considerados positivos.

\section{Análise de micro-organismos aeróbios mesófilos}

A contagem padrão em placas utilizada para quantificar as bactérias aeróbias mesófilas foi feitas através da técnica do "Pour Plate", no qual foram retirada $1 \mathrm{~mL}$ de cada uma das 3 diluições das amostras e adicionadas em Placas de Petri esterilizadas. Logo em seguida foi adicionado $15 \mathrm{ml}$ de ágar padrão para contagem (PCA). Misturou-se o inóculo com o meio de cultura movimentando suavemente as placas numa superfície plana, em movimentos em forma de oito. Após a completa solidificação do meio de cultura as placas foram incubadas em estufa a $35^{\circ} \mathrm{C}$, por 24 horas. O procedimento foi feito em duplicata para todas as diluições.

\section{Isolamento de E.coli e Identificação bioquímica das cepas}

Para o isolamento e identificação de Escherichia coli foram retiradas alíquotas dos tubos positivos de EC e estriados na superfície de placas contendo Agár eosina azul de metileno (EMB). As placas foram incubadas a $36^{\circ} \mathrm{C}$ por $24 \mathrm{~h}$.

As colônias que apresentaram crescimento característico de coliformes, Verde- Brilhante, foram semeadas em tubos de ensaio contendo ágar triptose soja (TSA) inclinado. Os tubos de TSA foram incubados em estufa a $35^{\circ} \mathrm{C}$ por 24 horas. Após esse período as cepas isoladas foram submetidas aos testes bioquímicos do IMVIC: Indol, Vermelho de Metila (VM), Vogues Proskauer (VP), Citrato de Simmons de acordo com Konemam e colaboradores (1993).

\section{RESULTADOS E DISCUSSÃO}

Os primeiros grupos de microorganismos a ser estudado foram os coliformes totais e termotolerantes, que quando presentes em alimentos fornecem informações sobre prováveis contaminações de origem fecal, de presença de patógenos ou 
ainda sobre o potencial de deterioração do produto, além de indicarem se as condições sanitárias foram inadequadas durante $\mathrm{o}$ processamento, produção ou armazenamento de um alimento (FRANCO; LANDGRAF, 2005).

O NMP de coliformes termotolerantes nas amostras nos quatro pontos variou de 4,0 a $5,4 \times 10^{2} \mathrm{NMP} / \mathrm{g}$. A presença de coliformes indica contaminação por interferência externa do alimento, principalmente pelo microorganismo Escherichia coli componente natural da flora intestinal humana, é a mais conhecida e a mais facilmente diferenciada dos membros não fecais, sendo o melhor indicador de contaminação fecal conhecido (SILVA JÚNIOR, 2001).

A RDC no 12/2001 (BRASIL, 2001), que dispõe sobre o regulamento técnico para padrões microbiológicos para alimentos destinados ao consumo humano, traz através do item 22 do anexo I da RDC n ${ }^{\circ} 12$, de 02 de janeiro de 2001, valores máximos para coliformes termotolerantes de $10^{2} \mathrm{NMP} / \mathrm{g}$ em "pratos prontos para consumo" considerando tanto alimentos à base de pescado cru como à base de cereias. Com base nessa legislação duas amostras encontram-se fora dos limites estabelecidos.
O NMP de coliformes totais variou de 1,4 a $5,4 \times 10^{2} \mathrm{CT} / 100 \mathrm{~mL}$. Embora não exista um limite estabelecido para o número de coliformes totais presentes, esse número encontrado é considerado significativo quando se tratando de alimentos para consumo humano (ALVES; ODORIZZI; GOULART, 2002).

A quantificação de micro-organismos mesófilos visa verificar a contaminação geral de um alimento e tem sido usada como indicador da qualidade higiênica dos alimentos, fornecendo também uma ideia sobre o seu tempo útil de conservação. (FRANCO; LANDGRAF, 2008)

O número de bactérias aeróbias mesófilas variou de $7,3 \times 10^{3} \mathrm{UFC} / \mathrm{mL}$ a $1,8 \times 10^{4} \quad$ UFC/mL. Segundo Jay (2005) e Forsythe (2002), contagens acima de $10^{6}$ $\mathrm{UFC} / \mathrm{g}$, podem ser responsáveis pelo desencadeamento de doenças de origem alimentar. Os resultados obtidos encontram-se abaixo desse valor, não oferecendo riscos de doenças. Os aeróbios mesófilos são considerados como índice de sanidade, e sua ausência indica que as condições de conservação foram adequadas (JAY, 2005). 
Tabela 1- Número Mais Provável (NMP) de coliformes totais (CT), coliformes termotolerantes (CTT), contagem de micro-organismos aeróbios mesófilos e pesquisa de Escherichia coli nas amostras de sushi coletados em Sobral-CE.

\begin{tabular}{cccc}
\hline Pontos & $\begin{array}{c}\text { Coliformes Termotolerantes } \\
(\mathrm{NMP} / \mathrm{g})\end{array}$ & $\begin{array}{c}\text { Coliformes Totais } \\
(\mathrm{NMP} / \mathrm{g})\end{array}$ & $\begin{array}{c}\text { Aeróbios mesófilos } \\
(\mathrm{UFC} / \mathrm{g})\end{array}$ \\
\hline NE1 & $1,1 \times 10$ & $1,4 \times 10^{2}$ & $9,95 \times 10^{3}$ \\
\hline NE2 & $5,4 \times 10^{2}$ & $5,4 \times 10^{2}$ & $7,3 \times 10^{3}$ \\
\hline NE3 & 4,0 & - & $7,3 \times 10^{3}$ \\
\hline E1 & $2,1 \times 10^{2}$ & $2,1 \times 10^{2}$ & $1,8 \times 10^{4}$
\end{tabular}

*UFC: Unidades Formadoras de Colônias

O resultado que foi obtido nesta pesquisa foi inferior ao encontrado no estudo de Martins (2006), feito na cidade de São Paulo, onde foi notificado valores acima de $10^{2} \mathrm{NMP} / \mathrm{g}$ em $50 \%$ das amostras de sushi e sashimi coletadas. Outro resultado considerado grave foi do trabalho de Pinheiro e colaboradores (2006), realizado na cidade de Fortaleza-CE, onde foram obtidos níveis de contaminação acima do permitido para coliformes termotolerantes em $30 \%$ das amostras de sushi e sashimis.

No teste bioquímico realizado $57,14 \%$ das cepas identificadas foram de Enterobacter cloacae, $15 \%$ de Escherichia coli, $14,29 \%$ de Proteus vulgaris e $14,29 \%$ de Hafnia alvei. Sendo todas as espécies da família Enterobacteriaceae.

Gráfico 1- Distribuição das cepas bacterianas identificadas nas amostras de sushi comercializadas em Sobral-CE.

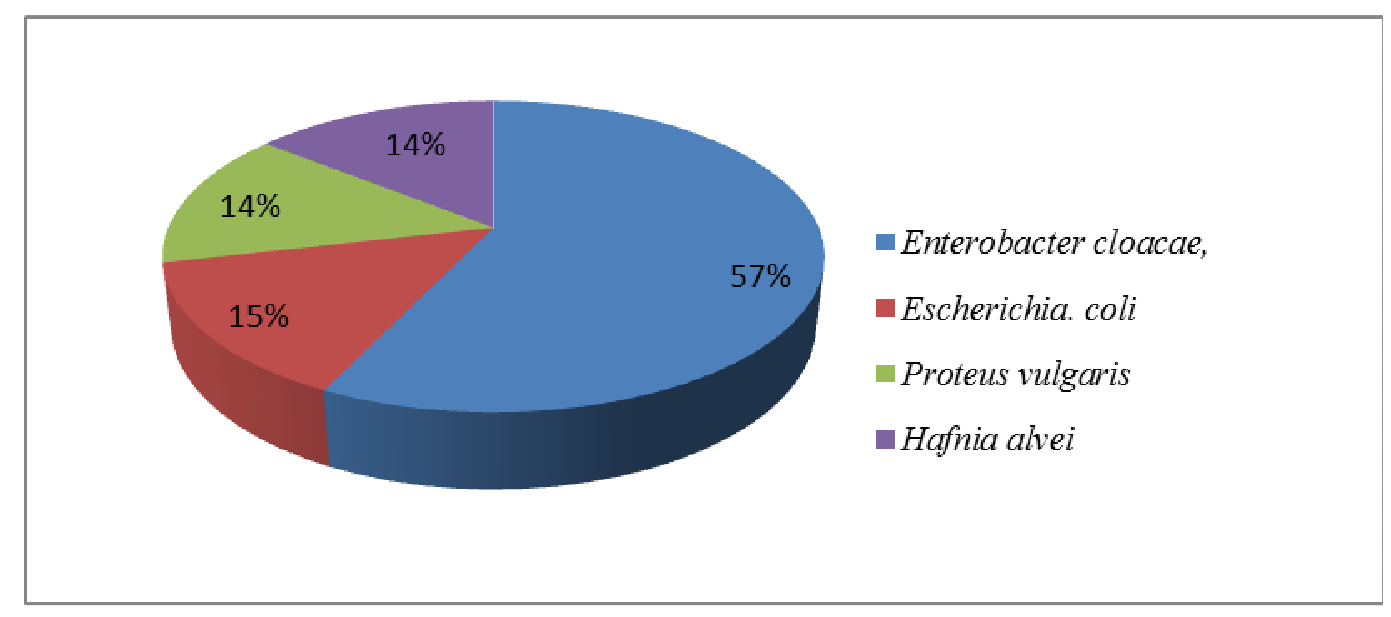


Estando presente em maior numero a bactéria Enterobacter cloacae são bactérias que causam infecções humanas em vários órgãos. Uma característica importante desta espécie é a capacidade de contaminar equipamentos médicos e soluções para uso paternal. Está envolvida em surtos de infecção hospitalar, em infecções urinárias e infecções respiratórias. (TRABULSI; ALTERTHUM, 2008)

Apresentando $\quad 15 \% \quad$ de contaminação, a Escherichia coli é a espécie predominante entre os diversos micro-organismos anaeróbicos facultativos que fazem parte da flora intestinal de animais de sangue quente. (FRANCO; LANDGRAF, 2008).

Proteus vulgaris, encontrados nas amostras (14\%), são bactérias que causam infecções urinárias e que produzem grandes quantidades de uréase que degrada a ureia formando amônia e outros produtos. Acredita-se que a alcalinização da urina durante as infecções urinárias causadas por estes organismos contribua para formação de cálculos urinários (TRABULSI; ALTERTHUM, 2008).

Hafnia alvei que apresenta em $14,29 \%$ no gráfico acima, ocorrem nas fezes de humanos e animais incluindo pássaros, água de esgoto, solo, água e produtos de origem animal e são bactérias que podem estar associadas a infecções extraintestinais, principalmente das vias biliares. Há trabalhos indicando que a espécie pode estar associada à diarreia de turistas e crianças (FARMER, 2003; TRABULSI; ALTERTHUM, 2008).

\section{CONSIDERAÇÕES FINAIS}

De acordo com os dados obtidos, foi possível observar a presença microorganismos indicadores de contaminação de origem fecal. Apesar do número de aeróbios mesófilos encontrarem-se dentro do encontrado na literatura, as amostras são consideradas impróprias pela presença de coliformes na mesma. Os estabelecimentos obtiveram erros graves em alguma etapa do preparo deste alimento e que os mesmos devem adotar medidas higiênicas sanitárias mais rigorosas, a fim de controlar os possíveis riscos potenciais à saúde do consumidor.

\section{REFERÊNCIAS BIBLIOGRÁFICAS}

ALVES, N. C.; ODORIZZI, A. C.;

GOULART, F. C. Análise

microbiológica de águas minerais e de 
água potável de abastecimento, Marília,

S.P. Revista Saúde Pública, São Paulo, v.36, n. 6, p.749-751, 2002.

BARBER, K.; TAKEMURA, H. Taste and Technique - DK Publishing, 2002.

BRASIL, Ministério da Saúde.

Resolução RDC n ${ }^{\circ} 12$ de 02 de janeiro de 2001 da Agência Nacional de Vigilância Sanitária-ANVISA. Regulamento técnico sobre padrões microbiológicos para alimentos. Diário Oficial da União. Brasília, 10 jan. 2001.

CORREIA, M.; RONCADA, M.J.

Características microscópicas de queijos prato, mussarela e mineiro comercializados em feiras livres da Cidade de São Paulo. Revista Saúde Pública. Vol. 31, 2002; 296-301p.

EDWARD, Paige. Global sushi: eating and identity. Perspectives on Global Development and Technology, v.11, n.1, p.211-225, 2012.

FARMER, J. J. Enterobacteriaceae: introduction and identification, p. 636653. In P. R.Murray, E. J. Baron, J. H. Jorgensen, M. A. Pfaller, and R. H.
Tolken (ed.), Manual of clinical microbiology, 8th ed. ASM Press, Washington, D.C. 2003.

FRANCO, B.D.G.M.; LANDGRAF, M. Microbiologia dos alimentos. São Paulo: Atheneu, 2005.

MALAVOTA, L.C.M. Avaliação dos Pontos Críticos no Processamento de sasshimis em restaurantes: Análises

Bacteriológicas e pesquisa de sensibilidade a Antimicrobianos.

Dissertação (Mestrado em Higiene Veterinária e Processamento Tecnológico de Produtos de Origem Animal) - Universidade Federal Fluminense e Faculdade Veterinária. Niterói, Rio de Janeiro; 2008).

\section{MARTINS, F. O. Avaliação da} qualidade higiênico-sanitária de preparações (sushi e sashimi) a base de pescado cru servidos em bufês na cidade de São Paulo. Dissertação de Mestrado. Universidade de São PauloUSP; São Paulo; 2006.

PINHEIRO, H. M. C.; VIEIRA, R. H. S. F.; CARVALHO, F. C. T.; REIS, E. M. F.; SOUSA, O. V.; VIEIRA, G. H. F.; RODRIGUES, D. P. Salmonella sp. 
E Coliformes Termotolerantes em Sushi

e Sashimi Comercializados na cidade de

Fortaleza-Ceará. Boletim Técnico.

Científica CEPENE; vol. 1; n.1; 2006;

23-31p.

SANTOS A.C. M; ZIDKO, A.C. M.;

PIGNATARI, A.C.C.; GALES, A.C.;

SILVA, R.M. A virulência de

Escherichia coli patogênica extra-

intestinal (ExPEC) em relação à idade e

ao sexo do hospedeiro. O Mundo da

Saúde, São Paulo: 2009; pg 392-400.

SCHLUNDT, J. New directions in

foodborne disease prevention.

International Journal of Food

Microbiology, v.78, p.3-17, 2002.

SILVA JÚNIOR. E. S. Manual de controle higiênico-sanitário em

alimentos. 4. ed. São Paulo: Varela, p.

107, 2001.

TRABULSI, L.R.; ALTERTHUM, F.

Microbiologia. $5^{\text {a }}$ ed. São Paulo:

Atheneu, 2008. 